\title{
Occupational hazards faced by spinning mill workers
}

\author{
SUDHA BABEL, RUPALI RAJVANSHI AND SANGEETA SHARMA
}

Received: 30.09.2014; Revised: 15.11.2014; Accepted: 28.11.2014

See end of the paper for authors' affiliations

\section{RUPALI RAJVANSHI}

Department of Textiles and Apparel Designing, College of

Home Science, Maharana Pratap University of Agriculture and

Technology, UDAIPUR (RAJASTHAN) INDIA
ABSTRACT : Yarn spinning is a process of making or converting fibre materials into yarns for making textile fabric or products. In spinning mills, the fibres pass through various processes to convert them into yarn. Every spinning mill has different sections like opening, where the bails are opened. After that, fibres are fed to machines which pass through carding, combining machine finally twisting is done to convert into yarn. Every department has different number of workers to carry or supervise the work. All these processes lead to fibre dust and its quantum vary from section to section. Opening section has maximum fibre dust and it is minimum in spinning section. The workers engaged in spinning mills encounter different occupational health problems and for identification of their health problems, a questionnaire was developed. Thirty respondents were interviewed and observation of work environment was made. The results revealed that spinning mill workers were facing the problems related to coughing and sneezing, eye irritation, breathlessness due to presence of dust in the work environment. Sweating was due to work pressure. Workers were taking no precautionary measures to avoid the inhale the fibre dust. This being the predisposing factor causing health problem. Hence, the need arises for the use of appropriate protective clothing for preventive them to exposed to fibre dust.

KEY WORDS: Spinning mill workers, Occupational hazards, Fibre dust

— HOW TO CITE THIS PAPER : Babel, Sudha, Rajvanshi, Rupali and Sharma, Sangeeta (2014). Occupational hazards faced by spinning mill workers. Asian J. Home Sci., 9 (2) : 572-575. 